\title{
COMPARATIVE STUDY OF CHANGES IN PLATELET COUNT IN WOMAN WITH HYPERTENSIVE DISORDERS IN PREGNANCY (HDP) AND NORMAL PREGNANT WOMAN IN THIRD TRIMESTER
}

Naresh T. Pawaskar ${ }^{1}$, P. J. Yaranal ${ }^{2}$

\section{HOW TO CITE THIS ARTICLE:}

Naresh T. Pawaskar, P. J. Yaranal. "Comparative Study of Changes in Platelet Count in Woman with Hypertensive Disorders in Pregnancy (HDP) and Normal Pregnant Woman in Third Trimester". Journal of Evolution of Medical and Dental Sciences 2013; Vol. 3, Issue 09, March 3; Page: 2213-2219,

DOI: $10.14260 /$ jemds/2014/2128

ABSTRACT: OBJECTIVE: To determine the changes in platelet count in HDP and normal pregnant women and to compare with severity and complications of pregnancy. MATERIAL AND METHODS: Prospective hospital based comparative study conducted over a period of one and half years. Study population includes 100 pregnant women in third trimester. Out of which 50 were normal pregnant women and 50 were HDP women. After admission history, physical examinations done and directed for laboratory studies like platelet count using automated blood cell counter. OBSERVATION: In study group out of 50 women 24 (48\%) were between 21-25 yrs of age, showing more incidence in primigravida 35 (70\%). The 29 (58\%) had gestational hypertension and (14)28\% had mild to moderate thrombocytopenia with mean platelet count of 1.76 lakhs/cumm. In control group (7)14\% had gestational thrombocytopenia with mean platelet count of 2.07 lakhs/cumm. Overall 20\% hypertensive pregnant had thrombocytopenia. The incidence of the complications in the study group was 56\%. The mean platelet count in complications secondary to HDP was within normal range. CONCLUSION: The incidence of Gestational thrombocytopenia is $14 \%$. It doesn't have any effect on pregnancy. Perinatal outcome is basically favourable. Thrombocytopenia in HDP is of mild to moderate variety about $28 \%$ and rarely drops below severe level. HDP are affecting outcome of pregnancy in the form of complications without causing variation in the platelet count. Complications occuring are attributable to HDP but not due to thrombocytopenia.

KEYWORDS: Thrombocytopenia, hypertensive disorder pregnancy, platelet changes.

INTRODUCTION: HDP includes hypertensive disorders peculiar to pregnancy which occurs for the first time after 20 wks of gestation and disappears following delivery. ${ }^{1}$ It is the most common medical disorder encountered during pregnancy, complicating 2-3\% of pregnancies. ${ }^{2}$ It is classified in to Gestational hypertension, Preeclampsia, Eclampsia, Preeclampsia superimposed on chronic hypertension and chronic hypertension recommended by national high blood pressure working group (2000). ${ }^{3}$

In 2008 SOGC released revised guideline, simplified the classification in to two categories, preexisting or gestational with an option to add preeclampsia to either category if additional maternal or fetal symptoms, signs or test results support this. ${ }^{4}$ Preeclampsia is the hypertension with proteinuria after 20 weeks of gestation and sometime earlier when there are extensive changes in the chorionic villi. HDP is responsible for largest proportion of Maternal and Perinatal mortality rate. HDP is a special problem in south Asian country like India. The overall incidence being 5-15\%, more in primigravida $16 \%$ than in multigravida $7-10 \%$. 
The HDP is a disease of serious complications unless it is managed effectively. It has been well known that, changes in platelet count is due to hemodilution, increased platelet consumption and increased platelet aggregation driven by increased levels of ThromboxaneA2. ${ }^{6}$ The single most important sensitive finding in haemostatic defect is low platelet count. All other parameters including blood biochemistry increases except platelet count.

Thrombocytopenia is defined as platelet count less than 1.5 lacs/cumm or count below 2.5 percentile for pregnant woman ${ }^{6}$. The criteria to diagnose gestational thrombocytopenia (GT) are normal platelet count before pregnancy, occurrence in late gestation, no fetal or neonatal thrombocytopenia and complete recovery with normal count following delivery. It is classified as mild with platelet count of $100-150 \times 10^{9} / \mathrm{L}$, moderate $50-100 \times 10^{9} / \mathrm{L}$ and severe with less than $50 \times 10^{9} /$ L. $^{7}$

Thrombocytopenia is encountered in $7-8 \%$ of all pregnancies, can result from several pregnancy related conditions. ${ }^{6}$ Thrombocytopenia occurring during pregnancy creates a diagnostic as well as management problem. Asymptomatic thrombocytopenia is observed near term in about $5 \%$ of normal pregnancies and sometime severe, in about $15 \%$ of women with preeclampsia. ${ }^{8}$

Therefore the present study was undertaken to demonstrate the changes in platelet count in normal pregnancy and hypertensive pregnancy and to compare the platelet count changes with severity of the HDP and its complications.

MATERIALS AND METHODS: Prospective hospital based comparative study conducted over a period of one and half years. Study population includes 100 pregnant women in third trimester. Out of which 50 were normal pregnant women and 50 were HDP women. After admission history, physical examinations done and directed for laboratory studies like platelet count using automated blood cell counter. The inclusion criteria's are blood pressure more than 140/90 mmHg irrespective of age, parity, proteinuria and edema. The women with Twin pregnancies, Polyhydramnios, Placenta previa, uterine anomalies, Gestational diabetes, chronic hypertension, Epilepsy and Blood disorders are excluded. Blood pressure between $140 / 90$ to $160 / 110 \mathrm{mmHg}$ with proteinuria is considered mild HDP and blood pressure more than $160 / 110 \mathrm{mmHg}$ with $(2+)$ proteinuria is considered severe HDP. Blood pressure of more than 140/90 mmHg in second half of the pregnancy was grouped as gestational hypertension.

The blood pressure is recorded with Sphygmomanometer in right upper arm with left lateral position. The phase 1 and 4 Kortkoff's sound considered systolic and diastolic blood pressure respectively. If blood pressure recorded found above $140 / 90 \mathrm{mmhg}$ in two different occasions, taken $6 \mathrm{hrs}$ apart was labeled hypertensive and evaluated. Heat coagulation test was done to detect urine albumin and graded as $1+, 2+$ and $3+$ depending upon the amount of protein. Proteinuria more than $300 \mathrm{mg}$ for $24 \mathrm{hrs}$ was considered significant for the study. About $3 \mathrm{ml}$ venous blood is collected in $5 \mathrm{ml}$ syringe with 20 gauze needle and immediately transferred to EDTA bulb and submitted for Platelet count using Automated blood cell counter.

OBSERVATIONS: Table 1 shows HDP is common between 21-25yrs (48\%) of age group and Table 2. shows incidence of gestational hypertension (58\%) as a common occurrence. Table 3 shows no significant changes in platelet count observed in either group. In hypertensive group 4\% had 
moderate and $24 \%$ had mild thrombocytopenia, but in normal pregnancy just $14 \%$ had gestational thrombocytopenia. In both groups count returned back to normal following delivery.

Table 4: shows comparison between platelet count in normal pregnancy and HDP. The mean values observed in normal pregnancy is 2.07 lakhs/cumm with SD +/- 0.959 and $\mathrm{C} \mathrm{I}+/-0$. 2658. In HDP mean value observed 1.76 lakh/cumm with SD+/- 0.677 and C I +/- 0. 1878.

In HDP group with GH mean value was 1. 67 lakh/cumm with SD +/-0.331, Mild PE 1. 95lakh/ cumm with SD +/- 0.925 and in severe PE 1. 81 lakh/cumm with SD +/- 1.019. The observed parameters showed that fall in platelet count in HDP is of insignificant value.

Table 5: Shows comparison between complications of HDP and mean platelet count. Incidence of complications irrespective of severity of HDP is about 56\%. Even with complications there was no significant variation in platelet count.

DISCUSSION: The Hypertension is one of the complications of pregnancy, with incidence in present study about 7.6\%. Upadhyaya reported an incidence of HDP 10\% in all over India and Lewis (1965) reported 3 to 10\%. In general incidence in developing and industrial world is nearly similar.

Changes in hematological and biochemical parameters during pregnancy plays an important role in evaluation of the patient with hypertensive disease and further steps can be taken for treating the patient. Most reports of serial platelet counts during normal pregnancy have noted no changes in the platelet count as pregnancy progresses. ${ }^{9}$ Some studies have demonstrated slight but statistically insignificant fall in mean platelet count within normal range, which reflects development of the gestational thrombocytopenia. ${ }^{10}$

Thrombocytopenia occurs in approximately $10 \%$ of pregnant women ${ }^{11}$. The common cause being gestational hypertension in about $58.2 \%$ accounts for almost $3 / 4$ of all the cases ${ }^{12}$.

Present study constitutes incidence of gestational thrombocytopenia about $14 \%$. According to various studies Thrombocytopenia in HDP accounts for $21 \%{ }^{12}$ and in those with mild to severe form of preeclampsia ranges from 15\%-18\%13. The present study showed incidence of thrombocytopenia in HDP about 28\%.

The Thrombocytopenia in normal pregnancy is a diagnosis of exclusion, in which features are of mild to moderate degree. It is asymptomatic without preconceptional history of thrombocytopenia and return to normal within 2-12 wks. postpartum 14. Gestational thrombocytopenia doesn't cause any harm to either mother or fetus. Thus it appears that mild to moderately depressed platelet count poses no risk to perinatal outcome and no management is necessary except periodic monitoring. ${ }^{15}$

The Thrombocytopenia in HDP is mild to moderate type, rarely platelet count fall below severe level. A gradually falling platelet count can be noted before clinical manifestation of the HDP. It is explained that it might be related to abnormal vascular tone with resultant acceleration in the platelet destruction, platelet activation and coagulation defect. Severity of HDP and Thrombocytopenia observed are closely correlated, which indicate that thrombocytopenia is directly proportional to severity of HDP. As such study has not showed any significant correlation between severity of the disease and studied parameters.

In the present study, Platelet count has shown variations in both normal pregnant and HDP women. During pregnancy it is more pronounced one week before delivery ${ }^{13}$. $20 \%$ of the HDP 


\section{ORIGINAL ARTICLE}

patients develop thrombocytopenia, where platelet count $<1.5$ lakh/cumm. This occurs in $7 \%$ mild and $50 \%$ severe form of HDP women.

In the present study, mean platelet count was 2.07 lakh/cumm and 1.76 lakh/cumm in normal pregnancy and HDP pregnancy respectively. It suggests that HDP studied in the present study is of non-thrombocytopenic category. As the platelet count varies with severity of the disease, we have tried to find out mean platelet count depending upon the severity of the disease. It was about 1.66 lakhs/cumm, 1.95 lakhs/cumm and 1.81 lakh/cumm in gestational hypertension, mild and severe preeclampsia respectively, with statistically insignificant $p$-value. The platelet count showed improvement from second post partum day.

The study conducted by Mahapatra $S$ et al showed mean platelet count in normal pregnancy 2.38 +/- 0.33lakhs/cumm and in HDP 2.23 +/- 0.19lakhs/cumm in Gestational hypertension, 1.82+/0.45 lakhs/cumm in preeclampsia, and 1.21+/-0.49 lakhs/cumm in eclampsia, suggestive of non thrombocytopenic type of HDP. The disease gets worsened with severity of hypertension with complications, showing inverse relationship between Platelet count and severity of HDP. 16

Thrombocytopenia appears to be characteristic of HDP associated with the complications and it doesn't occur in essential hypertension. Perinatal outcome depends upon the severity of HDP without alteration in Platelet count. In present study platelet count was within normal range even with complications of HDP. So neither it has diagnostic value nor prognostic value.

The mean platelet count was 1.51 lakh/cumm in present study, which is towards lower limit of the normal range. Fegurson et al (1956) showed in 10 patients mean platelet count 1.54 lakh/cumm in HDP group and in 12 patients with Abruptio placenta count was 1.2 lakh/cumm in his study. Thorbun at el (1982) showed mean platelet count in mild form 1.82+/-18 l/cumm and in severe form $1.73+/-18$ with no gross variations in severity.

Thrombocytopenia in pregnancy is an incidental finding, it can occur in normal pregnancies as gestational thrombocytopenia and pregnancies associated with complications like HDP, HELLP syndrome. Hence it is proved that, extent of fall in platelet count occurs proportional to severity of the disease, Mild to moderate fall in count is acceptable in normal pregnancy and HDP as well, requiring no treatment.

Maternal mortality was zero and perinatal mortality was $4 \%$ due to associated complications of the HDP. Generally, it ranges from 1-8\%. Platelet count was within normal limit. The Platelet count altered before delivery comes to normal following delivery. Hence platelet count is not directly related to complications of the pregnancy.

CONCLUSION: The incidence of Gestational thrombocytopenia is $14 \%$ and doesn't have any effect on pregnancy. Perinatal outcome is basically favourable. Thrombocytopenia in HDP is of mild to moderate variety, about $28 \%$ and rarely drops below severe level. HDP are affecting outcome of pregnancy in the form of complications without causing variation in the platelet count. Complications occuring are attributable to HDP but not directly to thrombocytopenia.

\section{REFERENCES:}

1. Cunningham P G, Norman F Gant, Kernath J. William obstetrics international edn. Edn $21^{\text {st }} \mathrm{New}$ York: 2001:567-568. 
2. Paul Gibson M D, Thomus Chin Chang Peng M D. Hypertension and Pregnancy update Oct 28: 2011.

3. Report of NHBC programme working group on high blood pressure in pregnancy. Am J Obstet gynecol: Jul2000; 183(1): S1-S22.

4. MageeL A, Helewa M, Moutquin J M. Diagnosis. Evaluation and management of hypertensive disorder of pregnancy. Jr of obstetric and gynecology Canada; march 2008; (30):1-48.

5. Dutta DC. Edn 3rd Text book of Obstetrics including Perinatology and Contraception. India, New central agency; 1989.

6. Enrique Vazgnez, Veva M D. Update on Thrombocytopenia in pregnancy. Jan13 2012.

7. Michal Parnas, Eyal Sheiner, Ilana Shoham Vardi, Eliezer Burstein, Tikra Yrmiahu, Itai Levi, et al. Moderate to severe thrombocytopenia during pregnancy. E J O G Reproductive biology (30) 2006.

8. Burrows R F, Kelton G J. Fetal thrombocytopenia and its relation to maternal thrombocytopenia. N Engl J Med. 1993; 329:1463-6.

9. Minakami H, Kuwata T, Sato I. Gestational thrombocytopenia: is it new? Am J Obstet gynecol 1996; 175: 1676.

10. Verdy E, Bessous V, Dreytus M, et al. Longitudinal analysis of platelet count and volume in normal pregnancy. Thromb hemost 1997; 77:806-7.

11. Sainto S, Kekomaki R, Rukonen S. Maternal thrombocytopenia a population based study. Acta Obstet gynecol; Scand 2000; 79:744-9.

12. Shehata N, Burrows R, Kelton JG, Gestational thrombocytopenia. Clinical obstetric gynecology 1992; 42:327-34.

13. Sullivan CA, Martin J M Jr. Management of obstetric patient with Thrombocytopenia. Clin obstret gynecol 1995; 38; 521-34.

14. Silver R, Berkovitz R, Bussel J. Thrombocytopenia in pregnancy. Practice bulletin no: 6. American college of obstetric and gynecology.

15. Nagey DS, Alger LS, Edelman BB, Heyman M R. Reacting appropriately to thrombocytopenia in pregnancy. South Med J 1986; 79:1385-8.

16. Mahapatra S, B Pradhan, U K Satpathy, Arati M. Platelet estimation; its prognostic value in HDP. Indian Jr physiol pharmacol: 2007 Apr-Jun; 51(2):160-4.

\begin{tabular}{|c|c|c|c|c|c|}
\hline $\begin{array}{c}\text { Age } \\
\text { (years) }\end{array}$ & $\begin{array}{c}\text { Mild } \\
\text { PE }\end{array}$ & $\begin{array}{c}\text { Severe } \\
\text { PE }\end{array}$ & $\begin{array}{c}\text { Gestational } \\
\text { HTN }\end{array}$ & Total & Percentage \\
\hline 16 to 20 & 3 & 2 & 8 & 13 & 26 \\
\hline 21 to 25 & 4 & 6 & 14 & 24 & 48 \\
\hline 26 to 30 & 4 & 2 & 6 & 12 & 24 \\
\hline 31 to 35 & - & - & 1 & 1 & 2 \\
\hline Total & $\mathbf{1 1}$ & $\mathbf{1 0}$ & $\mathbf{2 9}$ & $\mathbf{5 0}$ & $\mathbf{1 0 0}$ \\
\hline \multicolumn{7}{|c|}{ Table $1:$ Age wise distribution of cases. } \\
\hline
\end{tabular}

PE-Pre eclampsia, HTN-Hypertension, HDP-Hypertensive disorders of pregnancy 


\begin{tabular}{|c|c|c|}
\hline Type & No. of cases & Percentage \\
\hline Mild PE & 11 & $22 \%$ \\
\hline Severe PE & 10 & $20 \%$ \\
\hline Gestational HTN & 29 & $58 \%$ \\
\hline Total & 50 & $100 \%$ \\
\hline
\end{tabular}

\begin{tabular}{|c|c|c|c|}
\hline Groups & $\begin{array}{c}\text { Platelet count } \\
\text { (Lakhs/comm.) }\end{array}$ & $\begin{array}{c}\text { On admission } \\
(\%)\end{array}$ & $\begin{array}{c}\text { On discharge } \\
(\%)\end{array}$ \\
\hline \multirow{3}{*}{ Control } & $1-1.5$ & $7(14 \%)$ & $3(6 \%)$ \\
\cline { 2 - 4 } & $1.5-2$ & $25(50 \%)$ & $30(60 \%)$ \\
\cline { 2 - 4 } & $>2$ & $18(36 \%)$ & $17(34 \%)$ \\
\hline \multirow{3}{*}{ Study } & $<$ One lakh & $2(4 \%)$ & $1(2 \%)$ \\
\cline { 2 - 4 } & $1-1.5$ & $12(24 \%)$ & $11(22 \%)$ \\
\cline { 2 - 4 } & $1.5-2$ & $24(48 \%)$ & $23(46 \%)$ \\
\cline { 2 - 4 } & $>2$ & $12(24 \%)$ & $15(30 \%)$ \\
\hline
\end{tabular}

Table 3: Changes in Platelet count in study and control groups

\begin{tabular}{|c|c|c|c|c|}
\hline Platelet count & Normal pregnancy & Gestational HTN & Mild pe & Severe pe \\
\hline $\begin{array}{c}\text { Mean } \\
\text { lakh/cumm }\end{array}$ & 2.07 & 1.67 & 1.95 & 1.81 \\
\hline +/_S D & 0.959 & 0.331 & 0.925 & 1.019 \\
\hline 95\%C I & 0.2658 & 0.1204 & 0.5236 & 0.5331 \\
\hline
\end{tabular}

Table 4: Correlation between platelet count and severity of HDP

SD-Standard deviation, CI-Confidence interval.

\begin{tabular}{|c|c|c|c|}
\hline Complication & HDP & Normal pregnancy & Mean platelet count \\
\hline Abruptio placenta & 1 & 0 & 1.52 \\
\hline IUGR & 9 & 4 & 2.03 \\
\hline IUD & 2 & 0 & 2.04 \\
\hline PTL & 10 & 0 & 2.01 \\
\hline F Distress & 6 & 1 & 1.60 \\
\hline
\end{tabular}

Table 5: Platelet changes in complications of HDP and Normal pregnancy

IUGR-Intra uterine growth restriction, IUD-Intra uterine death, PTL-Preterm labour 


\section{ORIGINAL ARTICLE}

\section{AUTHORS:}

1. Naresh T. Pawaskar

2. P. J. Yaranal

\section{PARTICULARS OF CONTRIBUTORS:}

1. Professor, Department of Obstetrics and Gynecology, Kannur Medical College, Kannur.

2. Professor, Department of Pathology, Kannur Medical College, Kannur.

\section{NAME ADRRESS EMAIL ID OF THE} CORRESPONDING AUTHOR:

Dr. Naresh Pawaskar,

Professor,

Department of Obstetrics and Gynecology, Kannur Medical College, Kannur.

E-mail: naresh_pavaskar@rediffmail.com

Date of Submission: 25/07/2013.

Date of Peer Review: 26/07/2013.

Date of Acceptance: 14/02/2014.

Date of Publishing: 27/02/2014 